\title{
Social Marketing Targeting Indigenous Peoples: A Systematic Review
}

\begin{abstract}
Social marketing is a discipline focused on the application of marketing principles to induce socially desirable behaviour change. As social marketing remains one of the main behaviour change approaches pursued by governments and international organisations, it is important to consider its use in relation to vulnerable groups that are particularly exposed to discriminatory practices, marginalisation, exclusion and destitution. The aim of this systematic review is to identify the extent to which Andreasen's (2002) six social marketing benchmark criteria were reported in social marketing interventions targeting Indigenous peoples. A total of 20 articles covering 13 social marketing interventions were identified for review. Although none of the interventions gave evidence that they addressed all six of the benchmark criteria, they appear to have been effective in challenging some of the issues faced by Indigenous peoples. However, the criteria of segmentation, exchange and competition remain underused in the identified interventions. Social marketing interventions targeting Indigenous peoples tend to rely on television and radio advertising, showing potential for more use of product, place and price to influence, facilitate and maintain socially desirable behaviour change.
\end{abstract}




\section{Social Marketing Targeting Indigenous Peoples: a Systematic Review}

\section{INTRODUCTION}

Social marketing is a discipline focused on the application of marketing principles to induce socially desirable behaviour change, such as reducing tobacco consumption or increasing healthy eating among target audiences. In 2013, the International Social Marketing Association, European Social Marketing Association and Australian Association of Social Marketing adopted a consensus definition of social marketing, stating that "social marketing seeks to develop and integrate marketing concepts with other approaches to influence behaviours that benefit individuals and communities for the greater social good" (2013). This definition prescribes that social marketing practice is "guided by ethical principles" in an attempt to bring about "social change programs that are effective, efficient, equitable and sustainable" (AASM, ISMA, ESMA, 2013). However, social marketing has been frequently criticised for being manipulative, expensive, unethical or a form of social control that leads to negative consequences, such as stigmatisation and social exclusion, thereby infringing on the rights and freedoms of individuals (Andreasen, 2002; Gurrieri et al., 2013). As social marketing remains one of the main behaviour change approaches pursued by governments and international organisations, it is important to consider its use with groups that are particularly exposed to the issues identified above.

One such group is Indigenous peoples who are vulnerable to discriminatory practices, marginalisation, exclusion and destitution (see, e.g., UN OHCHR, n.d.). There are over 370 million Indigenous peoples living across the globe, and although they represent 5 per cent of the world's population, they also represent 15 per cent of the world's poorest people (United Nations, 2008: 10). Even though there is no universally agreed definition of "Indigenous peoples", and in some parts of the world terms such as "ethnic minorities" or "ethnic groups" are used by governments, the working definition adopted in this research is based on that proposed by José Martínez Cobo (1986: 379), the Special Rapporteur of the Sub-Commission on Prevention of Discrimination and Protection of Minorities:

Indigenous communities, peoples and nations are those which, having a historical continuity with pre-invasion and pre-colonial societies that developed on their territories, consider themselves distinct from other sectors of the societies now prevailing in those territories, or parts of them.

The 2030 Agenda for Sustainable Development (in force since 1 January 2016), whose overall focus is on reducing inequality within and among countries, in its political declaration identifies Indigenous peoples as one of the vulnerable groups who "must be empowered" (United Nations, 2015: para. 23). The United Nations Declaration on the Rights of Indigenous Peoples (2007) calls upon States to promote their full and effective participation in all matters concerning them, and it has been widely recognised that the protection and promotion of rights of Indigenous peoples contributes to the strengthening of democracy and consolidation of peace. However, strong evidence has emerged from previous research that health inequalities exist between Indigenous peoples and non-Indigenous populations in countries 
with large numbers of Indigenous populations (Madill et al., 2014). As governments and international organisations employ social marketing interventions as one tool by which to address the aforementioned gap, it is important to establish an evidence-base for social marketing interventions targeting Indigenous peoples.

Although social marketing campaigns have been used for over 40 years to influence behaviours, more recently there has been increasing recognition of the need to review the existing and exponentially growing body of evidence emerging from evaluations of social marketing interventions. Systematic literature reviews, defined as "a systematic, explicit, and reproducible method for identifying, evaluating, and synthesizing the existing body of completed and recorded work produced by researchers, scholars, and practitioners" (Fink, 2005: 3), are now commonly used in the health sciences to integrate a large amount of information about different interventions in a succinct manner. Systematic literature reviews have therefore been growing in popularity in social marketing, with some recently published reviews focusing on areas such as alcohol consumption, and vulnerable audiences such as children and elderly (Kubacki et al., 2015a, b; Fujihira et al., 2015).

Social marketing benchmark criteria were originally developed by Andreasen (2002) to differentiate social marketing from other behaviour change approaches such as health education and health promotion. According to Andresen (2002), for an intervention to be classified as social marketing it should include at least one of the following components:

- behavioural objective aiming to achieve behavioural change;

- formative research that uses audience research to understand target audiences, pre-tests interventions and monitors their delivery;

- segmentation dividing target audience into smaller segments according to shared characteristics;

- marketing mix of product, price, place and promotion;

- exchange, which provides target audiences with opportunities to exchange their resources (e.g., time and money) for attractive tangible and intangible benefits; and

- competition defined as other behaviours, campaigns and offerings that compete for the target audience's time and attention.

Although several sets of social marketing criteria have been proposed in social marketing and health promotion literature over the last three decades (see, e.g., Lefebvre and Flora, 1988; French and Blair-Stevens, 2006; Robinson-Maynard et al., 2013), studies by Carins and Rundle-Thiele (2014), Kubacki et al. (2015a, b) and Fujihira et al. (2015) have argued that only the benchmarks proposed by Andreasen (2002) provide mutually exclusive criteria that can be used to analyse social marketing interventions. Further, Andreasen's benchmark criteria have been widely recognised as representing the unique characteristics of social marketing (Madill et al., 2014), and have been used in previous social marketing systematic reviews (Kubacki et al., 2015a, b; Fujihira et al., 2015). Nevertheless, they have not been used to date to review interventions specifically targeting Indigenous peoples. Previous research has indicated that social marketing interventions are more likely to achieve behavioural 
change if they employ as many of the six social benchmark criteria as possible (Carins and Rundle-Thiele, 2014). Therefore, the aim of this systematic review is to identify the extent to which Andreasen's (2002) six social marketing benchmark criteria can be identified in social marketing interventions targeting Indigenous peoples.

\section{METHOD}

\section{Search strategy}

In order to identify evaluations of social marketing interventions targeting Indigenous peoples, systematic literature review procedure adhering to the PRISMA-P Protocol (Shamseer et al., 2015) was followed. A search was conducted of English-language, peerreviewed sources published up to April 2016. In accordance with previous social marketing systematic reviews (Fujihira et al., 2015; Kubacki et al., 2015a, b), only studies selfidentifying as social marketing were selected, in order to exclude other behaviour-change approaches (e.g., law, education, public health, etc.), which was warranted to establish the presence of specific marketing benchmark criteria. Seven databases (EBSCO, Emerald, Proquest All Databases, Ovid All Databases, Sciencedirect, Taylor \& Francis and Web of Science) were searched using the following terms: Indigenous or "First nation*" or "First people*" or Natives or "Native people*" or "Native population*" or Aboriginal* or Aborigine* or Métis or "Torres Strait Islander*" or Inuit* or Maori or "American Indian*” or "Native Indian*" or "Native American*" AND "social marketing" AND intervention* or "Randomi?ed Controlled Trial" or evaluation or trial or campaign* or program* or study or studies. The results are presented in Table 1.

Table 1: Databases and articles retrieved in initial search

\begin{tabular}{|l|c|}
\hline \multicolumn{1}{|c|}{ Database } & Number of articles retrieved \\
\hline EBSCO All Databases & 28 \\
\hline Emerald & 0 \\
\hline ProQuest All Databases & 40 \\
\hline Ovid & 32 \\
\hline ScienceDirect & 0 \\
\hline Taylor\&Francis & 3 \\
\hline Web of Science & 64 \\
\hline Total & $\mathbf{1 6 7}$ \\
\hline
\end{tabular}




\section{Inclusion and exclusion criteria}

The combined searches of the seven databases identified 167 records that were imported into Endnote. After removing duplicate records, 87 articles remained. Further, unqualified records, including newspaper articles and conference papers, were also removed $(n=8)$. Both researchers then screened titles and abstracts, applying exclusion criteria to identify evaluations of social marketing interventions targeting Indigenous peoples. The exclusion criteria included the following: formative research $(n=15)$, papers not self-identifying as social marketing $(n=18)$, reviews and conceptual papers $(n=8)$, and interventions not targeting Indigenous peoples $(\mathrm{n}=24)$. A total of 14 articles presenting evaluations of social marketing interventions targeting Indigenous peoples were identified. Figure 1 presents the stages and results of the literature search process.

To further maximise search coverage, backward and forward searches were conducted to identify a further six relevant papers. A backward search involved examining the reference lists of journal articles to identify further sources on social marketing interventions that would fit the search criteria. Additionally, the forward search comprised searching author and intervention names within Google Scholar and university library databases to locate additional relevant academic papers relating to the initially identified interventions or other scholarly evaluations of interventions undertaken by the authors. A total of 20 articles, covering 13 social marketing interventions, were identified in that process.

\section{Data extraction}

Both researchers independently analysed all identified articles relating to each intervention with the aim of identifying any potential evidence of the interventions following each of Andreasen's (2002) six social marketing benchmark criteria. For an intervention to be classified as using a marketing mix (that is, the four Ps: product, place, price and promotion), it had to report at least two of the marketing mix elements. This procedure is consistent with previous literature reviews in social marketing (Carins and Rundle-Thiele, 2014; Kubacki et al., 2015a, b). In addition to the benchmark criteria, the following information was extracted from all studies to provide insight into the context of the identified interventions: location (i.e., country), targeted social issue and use of theory underlying the intervention. Previous research has indicated that using theory can enhance the outcomes of social marketing campaigns (Thackeray and Neiger, 2000). 
Figure 1: Flowchart of the literature search process

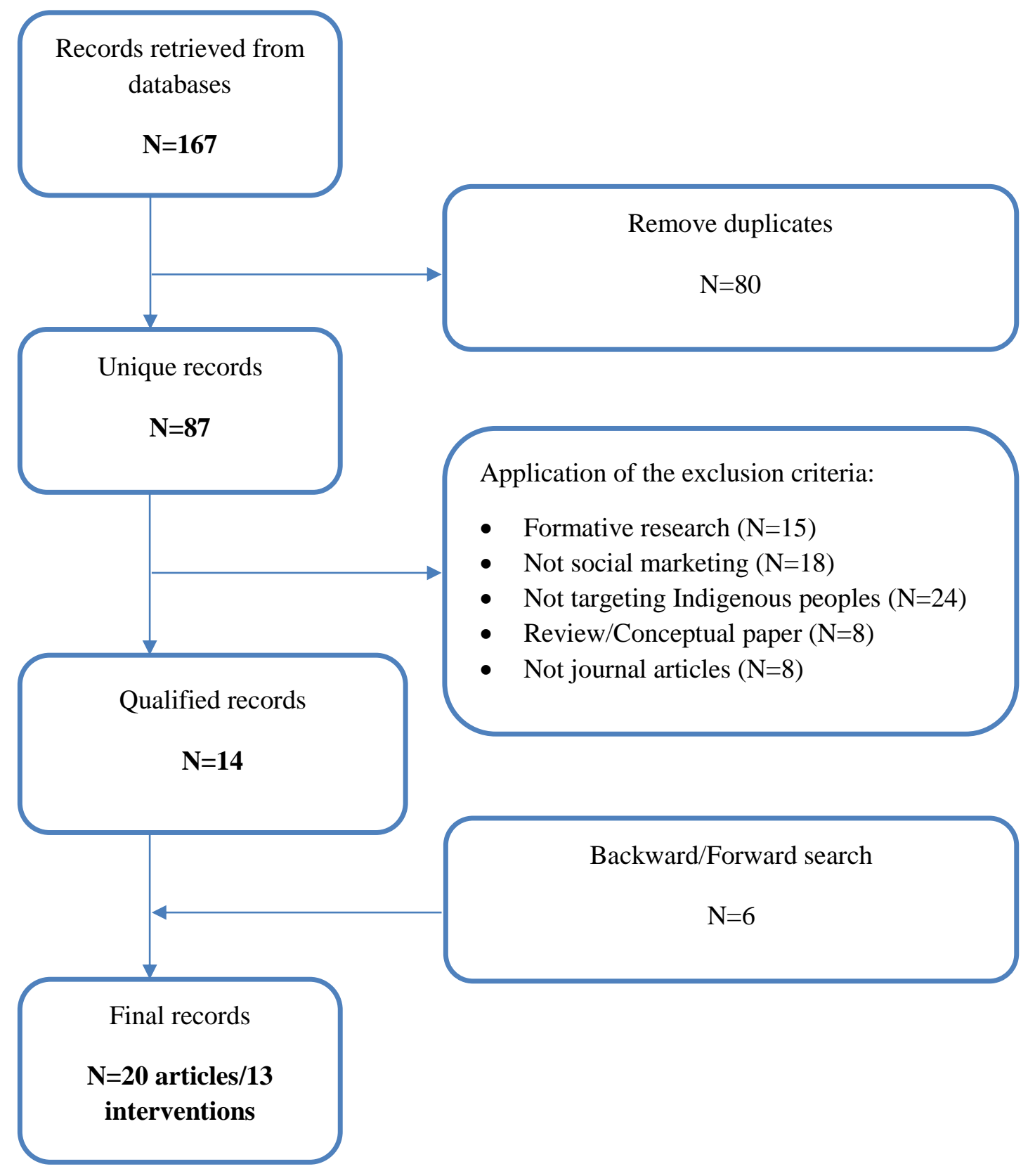

\section{RESULTS AND DISCUSSION}

Social marketing interventions were carried out in a diverse range of contexts. The results show that four interventions were carried out in Australia, four in the United States, three in New Zealand and two in Canada. Specific target audiences for each intervention are identified in Table 2.

The interventions attempted to address a wide range of social issues. Smoking was the target behaviour in four interventions (Campbell et al., 2014; Grigg et al., 2008; Maksimovic et al., 
2015; Wilson et al., 2005), followed by alcohol consumption in two interventions (Hanson et al., 2012; Jainullabudeen et al., 2015), physical activity in one intervention (Huhman et al., 2008) and prevention of type 2 diabetes and obesity via physical activity and good nutrition in one intervention (Bachar et al., 2006). Other social issues included prevention of cervical cancer (The National Social Marketing Centre Research Team, 2011), access to locally grown nutritious foods (Majid and Grier, 2010), hand-washing with soap to reduce high rates of diarrhoeal, respiratory (lung and ear) and skin infections (McDonald et al., 2011), reduction of iron deficiency anaemia among infants (Verrall and Gray-Donald, 2005), and promotion of breastfeeding (Wright et al., 1997).

Theory use was reported in only four interventions identified in this review. The health belief model and trans-theoretical (stages-of-change) model were used by The National Social Marketing Centre Research Team (2011); the theory of planned behaviour and ecological theory were used by McDonald et al. (2011); and community empowerment was reported in the study by Wright et al. (1997). Only one study reported using Indigenous theory - "Te whare tapa wha", a Māori framework for health - to develop the intervention (Grigg et al., 2008).

The assessment of each of the 13 social marketing interventions against Andreasen's (2002) six social marketing benchmark criteria indicates that none of the interventions addressed all six of the social marketing benchmark criteria, and only one intervention addressed five criteria (The National Social Marketing Centre Research Team, 2011) (see Table 2). Furthermore, 11 out of the 13 interventions reported the use of three or fewer benchmark criteria.

\section{Insert Table 2 About Here}

\section{Behavioural objective}

According to Andreasen's (2002) benchmark criteria, behaviour change should be the main focus of social marketing interventions. The behaviour change benchmark was identified in 10 out of 13 interventions, making it the most frequently employed benchmark criterion in interventions targeting Indigenous peoples. Further, the studies reviewed reported that all but one of those 10 interventions led to positive behavioural outcomes, with Maksimovic et al. (2015) reporting no difference between control and intervention groups. For example, Jainullabudeen et al. (2015) reported a decrease in the proportion of Indigenous individuals engaging in binge drinking, and a decrease in mean expenditure on alcohol among people who usually include alcohol in their activities with friends and family, following the intervention. Although Maksimovic et al. (2015) did not observe any statistical differences in terms of smoking cessation behaviours between smokers who had been previously exposed to their social marketing campaign and individuals who were not aware of it, individuals exposed to the campaign were more likely to introduce smoking bans at home.

Although social marketing has been previously criticised for causing negative consequences, such as stigmatisation and social exclusion of vulnerable groups (Andreasen, 2002; Gurrieri et 
al., 2013), it is important to note that none of the reviewed interventions reported any negative behavioural outcomes. Three interventions did not report any behavioural objectives, and focused instead on increasing awareness (Campbell et al., 2014; Hanson et al., 2012; Huhman et al., 2008); however, one reported positive behavioural change (Hanson et al., 2012).

\section{Formative research}

An equally commonly reported benchmark criterion was formative research, identified in 10 interventions. Only three did not report the use of any formative research methods (McDonald et al., 2011; Majid and Grier, 2010; Wilson et al., 2005), with one relying on evidence from two systematic literature reviews (McDonald et al., 2011). Primary formative research is an important component of social marketing as it provides insights into target audiences and their specific cultural characteristics and behaviours, creating an opportunity for social marketers to design interventions that address the needs and preferences of their end users. Social marketers must keep in mind that Indigenous peoples are not a homogenous group (Nicholls, 2009), and the cultural insight acquired through formative research should inform design of the marketing mix and segmentation approach. This is particularly important for interventions targeting vulnerable groups, such as Indigenous peoples, where culturally sensitive campaigns that engage target audiences are key to the success of social marketing.

The use of qualitative interviews was reported in six interventions (Bachar et al., 2006; Huhman et al., 2008; Jainullabudeen et al., 2015; The National Social Marketing Centre Research Team, 2011; Wright et al., 1997; Verrall and Gray-Donald, 2005). Focus groups were also reported in six interventions (Bachar et al., 2006; Campbell et al., 2014; Grigg et al., 2008; Hanson et al., 2012; The National Social Marketing Centre Research Team, 2011; Verrall and Gray-Donald, 2005). Quantitative surveys were reported only in three interventions (Bachar et al., 2006; Jainullabudeen et al., 2015; Wright et al., 1997), while observations were reported once (Verrall and Gray-Donald, 2005) and pilot-testing intervention materials was reported in four interventions (Grigg et al., 2008; Huhman et al., 2008; The National Social Marketing Centre Research Team, 2011; Verrall and Gray-Donald, 2005). Seven interventions reported the use of two or more formative research methods to provide better insights into target audiences (Bachar et al., 2006; Grigg et al., 2008; Huhman et al., 2008; Jainullabudeen et al., 2015; The National Social Marketing Centre Research Team, 2011; Verrall and Gray-Donald, 2005; Wright et al., 1997). For example, extensive formative research was reported by Wright et al. (1997), who attempted to develop a culturally sensitive campaign that would address perceived barriers to breastfeeding, relying on 35 ethnographic interviews, 250 questionnaires completed by postpartum women, and observations of interactions between women and practitioners in prenatal clinics, maternity wards and at well-baby clinics, as well as interviews with staff.

Even though it remains unclear what constitutes an Indigenous research method or methodology (Drawson et al., 2017), it is widely accepted that methods that incorporate Indigenous values, beliefs and ways of knowing produce more inclusive and respectful research and thus better address historical disempowerment of Indigenous peoples in research 
(see, e.g., The First Nations Information Governance Centre, 2014). No Indigenous research methods were reported in any of the identified interventions.

\section{Marketing mix}

Social marketing interventions should include all four elements of the marketing mix: product, place, price and promotion (Andreasen, 2002). However, only one intervention reported using the full marketing mix (Majid and Grier, 2010), and four other interventions reported using three Ps: product, place and promotion (Bachar et al., 2006; Wright et al., 1997), and product, price and promotion (The National Social Marketing Centre Research Team, 2011; Verrall and Gray-Donald, 2005).

All of the 13 social marketing interventions utilised promotional tools and activities. The reliance on promotion, communication and advertising materials in social marketing interventions has been identified in earlier systematic reviews (Carins and Rundle-Thiele, 2014; Fujihira et al., 2015; Kubacki et al., 2015a, b), and confusion between social marketing and social advertising has been recognised as one of the most important barriers limiting the effectiveness of social marketing (Grier and Bryant, 2005). Although Andreasen (2002) argued that social marketing should be more than just communication, in our review five interventions were found to rely solely on promotions and should therefore be classified as social advertising (Campbell et al., 2014; Huhman et al., 2008; Jainullabudeen et al., 2015; Maksimovic et al., 2015; McDonald et al., 2011). Furthermore, 11 interventions used print materials such as posters, brochures and leaflets; this was followed by advertising on television (Bachar et al., 2006; Grigg et al., 2008; Huhman et al., 2008; McDonald et al., 2011; The National Social Marketing Centre Research Team, 2011; Wilson et al., 2005) and radio (Campbell et al., 2014; Grigg et al., 2008; Hanson et al., 2012; Maksimovic et al., 2015; The National Social Marketing Centre Research Team, 2011; Wright et al., 1997), which were reported in six interventions each. Six interventions reported using events to promote intervention messages such as NAIDOC (National Aborigines and Islanders Day Observance Committee) week, which celebrates the history, culture and achievements of Aboriginal and Torres Strait Islander peoples (Jainullabudeen et al., 2015), and taste-testing events at grocery stores and cooking presentations (Majid and Grier, 2010; Verrall and Gray-Donald, 2005). Six interventions reported using free merchandise - such as T-shirts, a wallet card to remind women of their next smear test, footballs, drink bottles, temporary tattoos, and pens - and four interventions used outdoor media including bus shelters, bus interiors, billboards and venue advertisements. Two interventions reported using television documentaries; for example, Bachar et al. (2006) developed a seven-part television series of interviews with people who had experience with diabetes that was shown on a local cable channel, and Campbell et al. (2014) used short films starring local role models and broadcast in waiting rooms, at community events and on the Internet. Campbell et al.'s (2014) study was also the only intervention to report using Facebook or any other social media.

Although product is an important part of the marketing mix, as it is the only element that can provide a tangible or intangible benefit (e.g., a service facilitating the adoption of desired behaviour) to the target audience (Lee and Kotler, 2011), evidence of product use was 
identified in only six interventions. Three interventions reported telephone services such as quit line (Hanson et al., 2012; Wilson et al., 2005), and a toll-free number providing women with information on smear-taking services and frequently asked questions (The National Social Marketing Centre Research Team, 2011), respectively. Bachar et al. (2006) reported the most extensive use of different types of social marketing products to change behaviours, including exercise classes and classes on exercise techniques, walking groups, nutritional assessment, supermarket tours and pedometers. Other products included cooking activities (Verrall and Gray-Donald, 2005), discounted healthy foods (Majid and Grier, 2010), and home-based smear-testing services for groups of women (The National Social Marketing Centre Research Team, 2011).

Only four interventions reported identifying places in which the target audience can enter into an exchange and change their behaviour for the better. Bachar et al. (2006) identified elementary school, worksites and local churches as locations at which the intervention could increase physical activity and improve healthy eating; Hanson et al. (2012) identified community centres, health clinics, local schools and local tribal colleges, women's restrooms, clinics, tribal college buildings, obstetrics wards, domestic violence shelters, homeless shelters, and local food banks. Verrall and Gray-Donald (2005) used school kitchen facilities, community health clinics, grocery stores, and day-care centres to promote iron-rich foods and reduce iron-deficiency anaemia among infants. Finally, Majid and Grier (2010) reported that 135 communities were identified as eligible to receive subsidised healthy food.

Price relates to what the target audience needs to sacrifice in order to enter into an exchange and change their behaviour. A reduction in the intervention product's financial cost was identified as a marketing strategy in two interventions. The National Social Marketing Centre Research Team (2011) reported that free smear tests were provided to unscreened and underscreened women to encourage behaviour change. In Majid and Grier's (2010) study, healthy foods were subsidised to reduce their prices by an average of 15-20 per cent.

\section{Exchange}

Attractive and motivational exchange is a crucial component of any intervention (Andreasen, 2002). In the process of exchange, target audience members need to give up something tangible (e.g., cash) or intangible (e.g., time) to obtain the desired bundle of benefits delivered by the intervention. In this review, only two interventions reported any evidence of exchange; in both cases, products were offered in the interventions to their target audiences in exchange for money. The National Social Marketing Centre Research Team (2011) reported that they were unable to provide sufficient funding to make all smear tests free, and only high-priority women received them free of charge. The Food Mail Program aimed to increase access to nutritious and affordable food in the Canadian North by subsidising food transport so local Aboriginal population could access healthy food at reduced prices (Majid and Grier, 2010).

\section{Segmentation}


Social marketing segmentation attempts to increase the efficiency and effectiveness of available resources by dividing target audiences into smaller groups and tailoring interventions to their specific needs and requirements (Andreasen, 2002). An umbrella review of the use of segmentation in social marketing interventions indicates that it remains an underutilised marketing strategy, with only 16 per cent of social marketing interventions reporting the use of segmentation (Kubacki et al., 2017). In this review, following earlier systematic literature reviews in social marketing (Fujihira et al., 2015; Kubacki et al., 2015b), evidence of at least one element of the marketing mix (product, price, place or promotion) being adapted to different segments within the campaign's target audience had to be reported. As resources available to support social marketing interventions targeting Indigenous peoples remain very limited, a one-size-fits-all approach dominated in this review, with only one intervention reporting the use of segmentation. The National Social Marketing Centre Research Team (2011) reported that in their intervention aiming to encourage women to participate in cervical screening, due to limited funding free smear tests were provided only to high-priority women including the unscreened or under-screened.

\section{Competition}

Social marketing interventions need to recognise and understand what other behaviours compete for the intervention audience's time and attention, and identify engagement strategies that will be effective in attracting the audience's interest (Andreasen, 2002). There are two types of competition: direct competition, which includes other social marketing and public health campaigns that aim to engage the same target audience; and indirect competition, including other behaviours that attract the target audience's time and attention. Only one intervention in this review mentioned any form of competition. Bachar et al. (2006) recognised that childhood obesity is augmented by soft-drinks consumption and eating food containing energy-dense fats and sugars, and they identified in their intervention area more than 19 fast-food restaurants.

\section{Limitations}

This study suffers from several important limitations, which should be considered as opportunities for further research. First, it includes only studies that self-identified as social marketing; thus, future work should explore other educational and public health interventions that may contain elements of social marketing. Second, all identified interventions were conducted in Western contexts; therefore, future research should seek to analyse efforts in non-Western contexts, which may require extending the review procedures beyond peerreviewed studies and/or articles in the English language. Third, this paper employed Andreasen's (2002) benchmark criteria; therefore, opportunities exist to analyse the identified studies using different approaches. As social marketing targeting Indigenous peoples remains an under-explored area, there are opportunities for further research to identify, for example, the most effective and culturally appropriate social marketing campaign designs. Further, as Andreasen's benchmark criteria do not account for cultural differences, additional analysis is 
required to identify specific cultural characteristics that may affect the design and delivery of social marketing campaigns targeting Indigenous peoples. Researchers have called for more work resisting essentialist positions and acknowledging differences within a collective identity of Indigenous peoples (Nicholls, 2009). Future research in social marketing thus needs to recognise that Indigenous peoples in a particular country or community may be a diverse group, which can be achieved by, for example, using segmentation tools and techniques (Dietrich et al., 2017). Finally, our review was limited to the information provided in the identified sources, which may not always include all information regarding these interventions. Further research could, however, be conducted using tools such the Evaluation of Public Health Practice Projects (2009) to provide assessment of studies included in this review.

\section{CONCLUSION}

This systematic review aimed to identify the extent to which Andreasen's (2002) six social marketing benchmark criteria were reported in social marketing interventions targeting Indigenous peoples. This study has identified 20 articles covering 13 interventions. All of the interventions were conducted in Australia, the US, New Zealand and Canada, which have large Indigenous populations ( 2 per cent, 0.9 per cent, 16 per cent and 3.8 per cent, respectively, of the total population; Dow and Gardiner-Garden, 1998) that are facing significant health, social and economic problems. Six interventions targeted harmful use of alcohol and tobacco, indicating that drug use among Indigenous peoples remains one of the top-priority areas for social marketing interventions.

None of the social marketing interventions reported using all six of Andreasen's (2002) benchmark criteria. As behaviour change is more likely to happen when more benchmark criteria are used (Carins and Rundle-Thiele, 2014), limited use of more than four benchmark criteria may restrict the effectiveness of social marketing interventions targeting Indigenous peoples. In line with previous systematic reviews (Fujihira et al., 2015; Kubacki et al., 2015a, b), segmentation, exchange and competition remain underused in social marketing.

Carins and Rundle-Thiele (2014) distinguished between social marketing interventions that make comprehensive use of the social marketing process, including formative research, behavioural objectives, competition analysis, segmentation and the marketing mix, and social advertising that focuses on the use of promotion, communication and advertising materials. Although the majority of interventions identified in our review appear to be effective in challenging some of the issues faced by Indigenous peoples, they rarely stretch beyond basic adaptation of social marketing tools such as promotion and they tend to (over-)rely on television and radio advertising, and so-called SPLAT (Some Posters, Leaflets, Ads and Things; French and Gordon, 2015). Further opportunities exist to increase the effectiveness of social marketing interventions through the use of Indigenous theories and research methods and methodologies (Chilisa, 2012; Wilson, 2008); in our review, only one intervention reported the use of Indigenous theory. 


\section{REFERENCES}

AASM, ISMA, ESMA (2013) Consensus definition of social marketing. Available at: http://www.i-socialmarketing.org/assets/social_marketing_definition.pdf.

Andreasen A.R. (2002) Marketing social marketing in the social change marketplace. Journal of Public Policy \& Marketing, 21 (1), 3-13.

Anon. (2015) Cherokee choices diabetes prevention program for Native American Cherokee Indians (USA-Government). Retrieved 22 February, 2017, from www.gken.org/Synopses/CI_10006.pdf

Bachar J. (2011a) Cherokee choices: a diabetes prevention program in Cherokee, North Carolina. North Caroline Medical Journal, 72(5), 394-395.

Bachar J. (2011b) REACHing eastern band of Cherokee Indians in Cherokee, North Caroline. Retrieved 22 February, 2017, from at: http://usphsicon.files.wordpress.com/2011/03/cherokee_choices.pdf

Bachar J.J., Lefler L., Reed L., McCoy T., Bailey R., Bell R. (2006) Cherokee Choices: a diabetes prevention program for American Indians. Preventing Chronic Disease, 3(3), A103A103.

Bethune G.R., Lewis H.J. (2009) Let's talk about smear tests: social marketing for the National Cervical Screening Programme. Public Health, 123, e17-e22.

Campbell M.A., Finlay S., Lucas K., Neal N., Williams R. (2014) Kick the habit: a social marketing campaign by Aboriginal communities in NSW. Australian Journal of Primary Health, 20(4), 327-333.

Carins J.E., Rundle-Thiele S.R. (2014) Eating for the better: a social marketing review (20002012). Public Health Nutrition, 17(7), 1628-39.

Chilisa B. (2012) Indigenous research methodologies. SAGE Publications Ltd, London.

Cobo J.M. (1986) Study of the Problem of Discrimination Against Indigenous Populations. UN Doc E/CN.4/ Sub.2/1986/7 and Add. 1-4.

Dietrich, T., Rundle-Thiele, S., Kubacki, K. (Eds)(2017) Segmentation in Social Marketing, Springer

Dow, C., Gardiner-Garden, J. (1998) Indigenous affairs in Australia, New Zealand, Canada, United States of America, Norway and Sweden. Parliament of Australia, 6 April 1998. $\begin{array}{llll}\text { Retrieved } \quad \text { February 22, from } & \text { 2017, }\end{array}$ http://www.aph.gov.au/About_Parliament/Parliamentary_Departments/Parliamentary_Library /Publications_Archive/Background_Papers/bp9798/98Bp15

Drawson, A.S., Toombs, E., Mushquash, C.J. (2017) Indigenous research methods: a systematic review. International Indigenous Policy Journal, 8(2), in press.

EPHPP (2009) Effective Public Health Practice Project: Quality Assessment Tool for Quantitative Studies. Retrieved February 22, 2017, from http://www.ephpp.ca/tools.html 
Fink, A. (2005) Conducting Research Literature Reviews: From the Internet to Paper, $2^{\text {nd }}$ ed., Thousand Oaks, California: Sage Publications.

French, J., Blair-Stevens, C. (2006) Social Marketing National Benchmark Criteria. London, England: National Social Marketing Centre. Retrieved February 22, 2017, from http://www.snh.org.uk/pdfs/sgp/A328466.pdf

French J., Gordon R. (2015) Strategic social marketing. SAGE Publications Ltd, London.

Fujihira H., Kubacki K., Ronto R., Pang B., Rundle-Thiele S. (2015) Social marketing physical activity interventions among adults sixty years old and older: a systematic review. Social Marketing Quarterly, 21(4), 214-229.

Grier S., Bryant C.A. (2005) Social marketing in public health. Annual Review of Public Health, 26, 319-339.

Grigg M., Waa A., Bradbrook S.K. (2008) Response to an indigenous smoking cessation media campaign - It's about whanau. Australian \& New Zealand Journal of Public Health, 32(6), 559-564.

Gurrieri L., Previte J., Brace-Govan J. (2013) Women's bodies as sites of control: inadvertent stigma and exclusion in social marketing. Journal of Macromarketing, 33(2), 128-143.

Hanson J.D., Winberg A. Elliott, A. (2012) Development of a media campaign on fetal alcohol spectrum disorders for Northern Plains American Indian communities. Health Promotion Practice, 13(6), 842-847.

Huhman M., Berkowitz J.M., Wong F.L., Prosper E., Gray M., Prince D., Yuen, J. (2008)“The VERB (TM) campaign's strategy for reaching African-American, Hispanic, Asian, and American Indian children and parents. American Journal of Preventive Medicine, 34(6), S194-S209.

Jainullabudeen T.A., Lively A., Singleton M., Shakeshaft A., Tsey K., McCalman J., Doran Ch., Jacups, S. (2015) The impact of a community-based risky drinking intervention (Beat da Binge) on Indigenous young people. BMC Public Health, 15, 1319.

Kubacki K., Rundle-Thiele S., Pang B., Buyucek N. (2015a) Minimising alcohol harm: a systematic social marketing review (2000-2014). Journal of Business Research, 68(10), 22142222 .

Kubacki K., Rundle-Thiele S., Lahtinen V., Parkinson, J. (2015b) A systematic review assessing the extent of social marketing principle use in interventions targeting children (2000-2014). Young Consumers, 16(2), 141-158.

Kubacki K., Rundle-Thiele S., Pang B., Carins J., Parkinson J., Fujihira H., Ronto R. (2017) Segmentation in social marketing: an umbrella review. In: Dietrich T., Rundle-Thiele S., Kubacki K. (Eds) Segmentation in social marketing. Springer.

Lee N., Kotler, P. (2011) Social marketing: Influencing behaviors for good (4th ed.). Thousand Oaks, CA: SAGE Publications. 
Lefebvre, R.C., Flora, J. A. (1988) Social marketing and public health intervention. Health Education Quarterly, 15, 299.

Madill J., Wallace L., Goneau-Lessard K., MacDonald R.S., Dion, C. (2014) Best practices in social marketing among Aboriginal people. Journal of Social Marketing, 4(2), 155-175.

Majid K., Grier, S. (2010) The Food Mail Program: 'When Figs Fly' - dispatching access and affordability to healthy food. Social Marketing Quarterly, 16(3), 78.

Maksimovic L., Shen D., Bandick M., Ettridge K., Eckert, M. (2015) Evaluation of the pilot phase of the 'Give up smokes for good' social marketing campaign. Health Promotion Journal of Australia, 26(1), 16-23.

McCalman J., Tsey K., Bainbridge R., Shakeshaft A., Singleton M., Doran Ch. (2013) Tailoring a response to youth binge drinking in an Aboriginal Australian community: a grounded theory study. BMC Public Health, 13, 726.

McDonald E., Slavin N., Bailie R., Schobben X. (2011) No germs on me: a social marketing campaign to promote hand-washing with soap in remote Australian Aboriginal communities. Global Health Promotion, 18(1), 62-65.

McDonald E., Cunningham T., Slavin N. (2015) Evaluating a handwashing with soap program in Australian remote Aboriginal communities: a pre and post intervention study design. BMC Public Health, 15, 1188.

Nicholls, R. (2009) Research and Indigenous participation: critical reflexive methods. International Journal of Social Research Methodology, 12(2), 117-126.

Robinson-Maynard, A., Meaton, J., Lowry, R. (2013) Identifying key criteria as predictors of success in social marketing: Establishing an evaluation template and grid. In: Kubacki, K, Rundle-Thiele, S. (Eds.) Contemporary Issues in Social Marketing. United Kingdom: Cambridge Scholars Publishing.

Shamseer L., Moher D., Clarke M., Ghersi D., Liberati A., Petticrew M., Shekelle P., Stewart L., PRISMA-P Group (2015) Preferred reporting items for systematic review and metaanalysis protocols (PRISMA-P) 2015: elaboration and explanation. The British Medical Journal, 349: g7647.

Thackeray R., Neiger, B.L. (2000) Establishing a relationship between behavior change theory and social marketing: Implications for health education. Journal of Health Education, 31, 331-335.

The First Nations Information Governance Centre (2014) Ownership, Control, Access and Possession (OCAP): The Path to First nations Information Governance. Ottawa: the First Nations Information Governance Centre, May 2014. Retrieved 27 June, 2017, from: www.fnigc.ca

The National Social Marketing Centre Research Team (2011) 'Don't Just SAY It Matters': Reducing the Inequalities in Cervical Screening in New Zealand. Social Marketing Quarterly, 17(4), 41. 
United Nations General Assembly (2007) United Nations Declaration on the Rights of Indigenous Peoples, 2 October 2007, A/RES/61/295.

United Nations (2008) Resource Kit on Indigenous Peoples' Issues. New York: United Nations Publications.

United Nations (2015) Transforming our World: The 2030 Agenda for Sustainable Development. United Nations, A/RES/70/1.

UN OHCHR [United Nations Human Rights Office of the High Commissioner] (n.d.) 'Combating Discrimination against Indigenous Peoples'. Retrieved 25 February, 2017, from: http://www.ohchr.org/EN/Issues/Discrimination/Pages/discrimination_indigenous.aspx

Verrall T., Gray-Donald, K. (2005) Impact of a food-based approach to improve iron nutrition of at-risk infants in northern Canada. Preventive Medicine, 40, 896-903.

Verrall T., Napash L., Leclerc L., Mercure S., Gray-Donald K. (2006) Community-based communication strategies to promote infant iron nutrition in northern Canada. International Journal of Circumpolar Health, 65(1), 65-78.

Wilson S. (2008) Research is ceremony: Indigenous research methods. Fernwood Publishing, Black Point, NS, Canada.

Wilson N, Grigg M., Graham L., Cameron, G. (2005) The effectiveness of television advertising campaigns on generating calls to a national Quitline by Maori. Tobacco Control, 14, 284-286.

Wright A.L., Naylor A., Wester R., Bauer M., Sutcliffe, E. (1997) Using cultural knowledge in health promotion: breastfeeding among the Navajo. Health Education \& Behavior, 24(5), 625-639. 
Table 2: Assessment of the use of Andreasen's social marketing benchmark criteria (SMBC) in social marketing interventions 


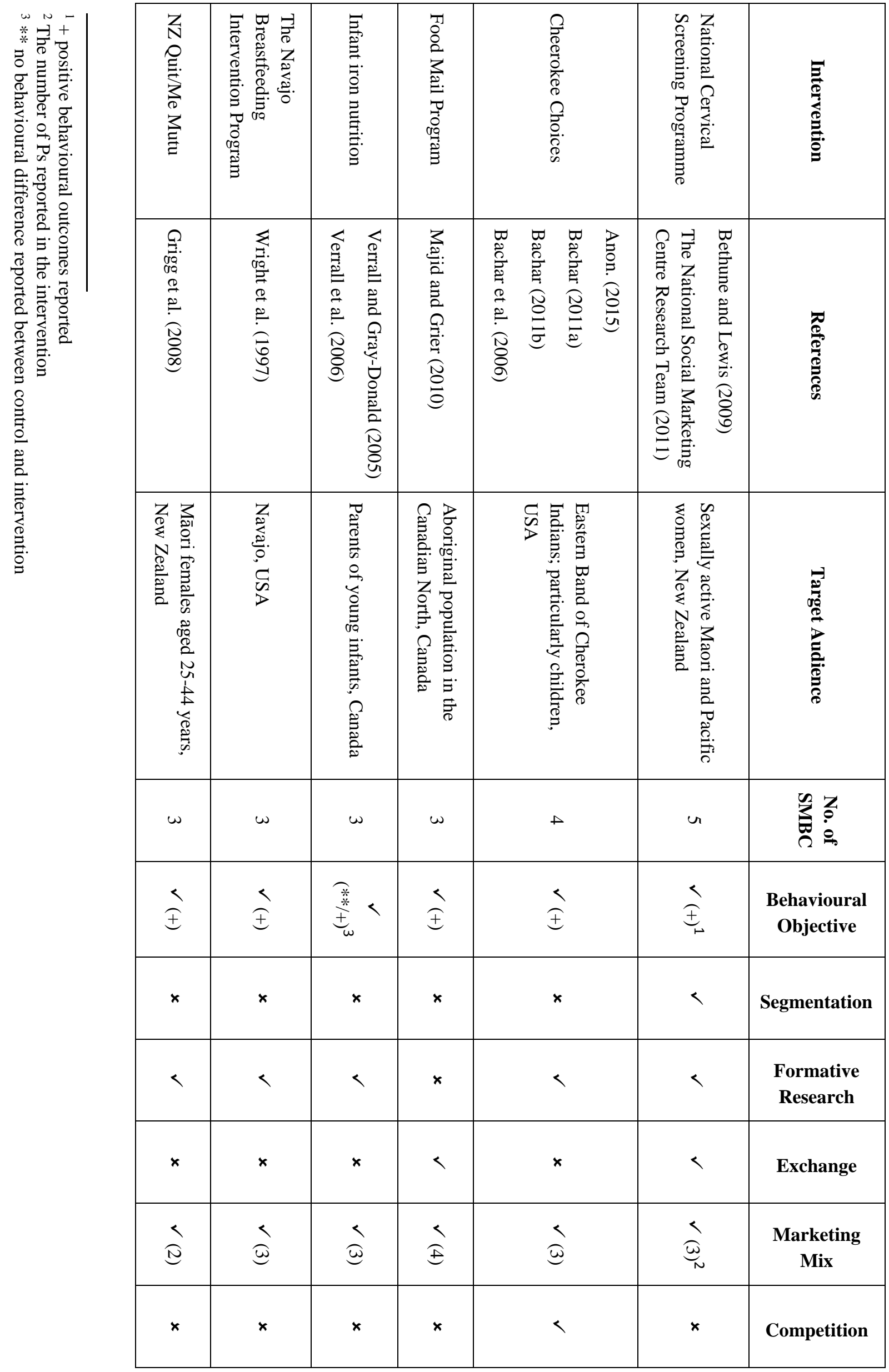




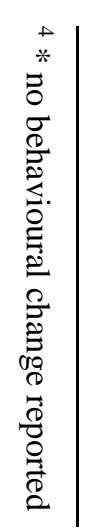

\begin{tabular}{|c|c|c|c|c|c|c|c|}
\hline 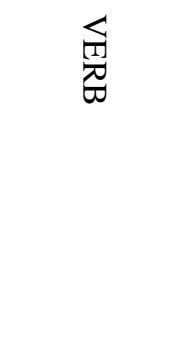 & 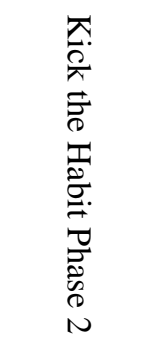 & 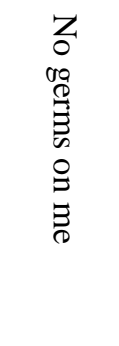 & 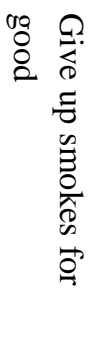 & 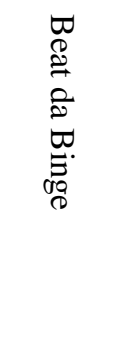 & 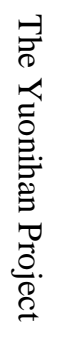 & $\begin{array}{l}\text { Z } \\
\text { N } \\
\text { O. } \\
\text { : } \\
\text { : }\end{array}$ & 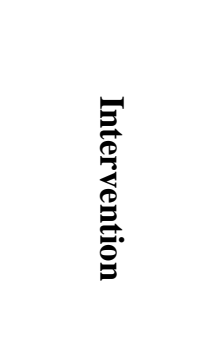 \\
\hline 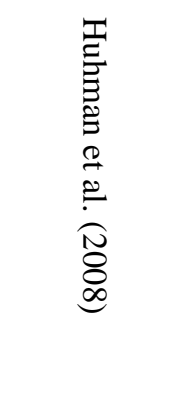 & 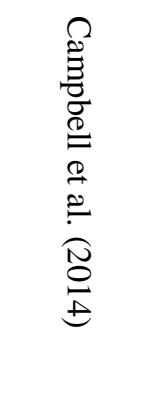 & 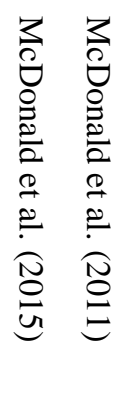 & 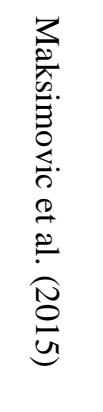 & 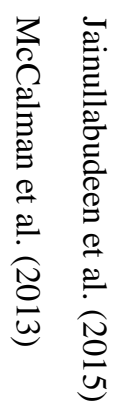 & 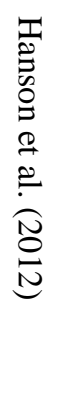 & 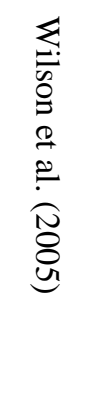 & 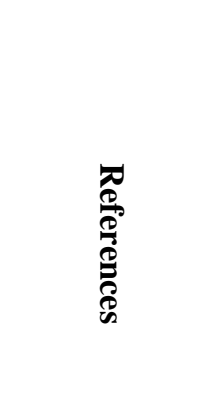 \\
\hline 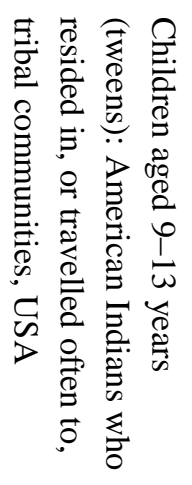 & 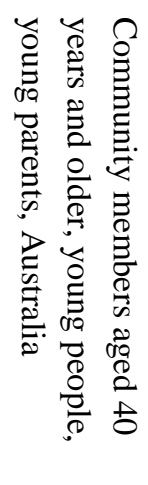 & 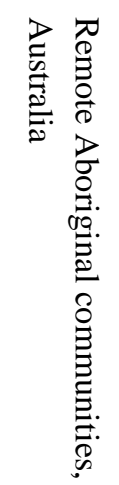 & 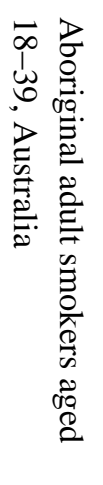 & 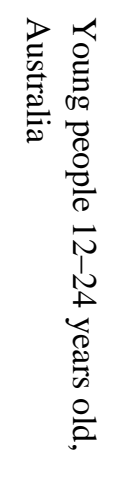 & 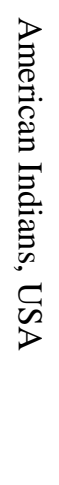 & 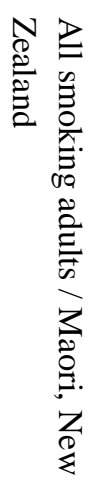 & 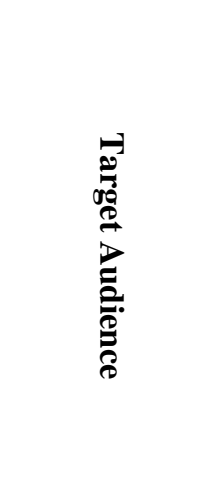 \\
\hline- & - & - & N & $N$ & $N$ & $N$ & 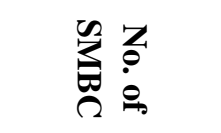 \\
\hline$\stackrel{x}{*}$ & $\underbrace{*}_{+}$ & $\stackrel{<}{ \pm}$ & $\stackrel{\stackrel{*}{*}}{\stackrel{*}{*}}$ & $\stackrel{<}{\ddagger}$ & $\stackrel{x}{\oplus}$ & $\stackrel{<}{ \pm}$ & $\begin{array}{c}\text { Behavioural } \\
\text { Objective }\end{array}$ \\
\hline$x$ & $x$ & $x$ & $x$ & $x$ & $x$ & $x$ & Segmentation \\
\hline$<$ & $<$ & $x$ & $<$ & $<$ & $<$ & $x$ & $\begin{array}{l}\text { Formative } \\
\text { Research }\end{array}$ \\
\hline$x$ & $x$ & $x$ & $x$ & $x$ & $x$ & $x$ & Exchange \\
\hline$\stackrel{x}{\Xi}$ & $\stackrel{x}{\Xi}$ & $\stackrel{x}{\Xi}$ & $\stackrel{x}{\Xi}$ & $\stackrel{x}{\Xi}$ & ì & ì & $\begin{array}{l}\text { Marketing } \\
\text { Mix }\end{array}$ \\
\hline$x$ & $x$ & $x$ & $x$ & $x$ & $x$ & $x$ & Competition \\
\hline
\end{tabular}

